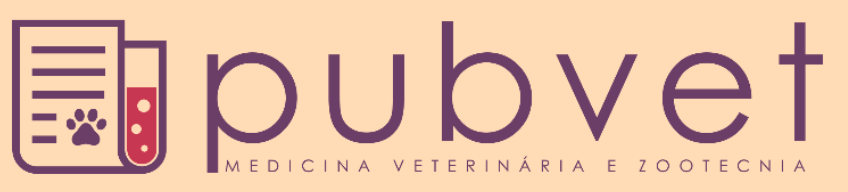

https://doi.org/10.31533/pubvet.v15n10a944.1-8

\title{
Mortalidade em tilápias (Oreochromis niloticus) provocada por falhas de manejo e o desafio diagnóstico para os serviços veterinários oficiais
}

\author{
Ricardo da Silva Raposo ${ }^{1 *} \bullet$, Nádia Valesca Biral de Oliveira $^{1 \bullet}$, Carlos Vinícius dos Santos \\ Oliveira $^{10}$, Helvécio Leal Santos Júnior ${ }^{2} \bullet$
}

${ }^{I}$ Secretaria de Agricultura, Abastecimento e Desenvolvimento Rural do Distrito Federal - SEAGRI/DF

${ }^{2}$ Laboratório de Anatomia Patológica Veterinária - União Pioneira de Integração Social - UPIS.

"Autor para correspondência, E-mail: ricardo.raposo@seagri.df.gov.br

\begin{abstract}
Resumo. As falhas de manejo estão entre as principais causas de mortalidade na piscicultura e por isso são importantes diagnósticos diferenciais durante investigações de doenças-alvo de peixes pelos serviços veterinários oficiais. Este artigo relata um caso de mortalidade total estimada em $70 \%$ ocorrida em um criatório de tilápias de Brasília/DF, provocada pelo excesso de arraçoamento, superpopulação de peixes e ausência de sistemas de aeração. As mortes foram provocadas pela hipóxia encontrada em quatro dos cinco tanques existentes, mediante análise da concentração de oxigênio dissolvido em cada unidade. $\mathrm{O}$ fato evidencia a importância dos kits de análise de água durante atendimentos a suspeitas de doenças de peixes, por se tratar de importante diagnóstico diferencial, principalmente em casos de alta mortalidade. Outro achado encontrado foi a presença de esteatose hepática nas oito tilápias necropsiadas, confirmado pela observação de degeneração gordurosa de hepatócitos em ensaios histopatológicos.
\end{abstract}

Palavras-chave: Oreochromis niloticus, esteatose hepática, manejo incorreto, serviço veterinário oficial

\section{Mortality in tilapia (Oreochromis niloticus) caused by management failures and the diagnostic challenge for official veterinary services}

\begin{abstract}
Management failures due to excess feed supply, fish overpopulation and dissolved oxygen deficit in water are among the leading causes of mortality in fish farming. Therefore, these failures are important differential diagnoses that should be considered during investigations of notifiable diseases by the official veterinary services. This article reports a case of estimated total mortality of $70 \%$ in a tilapia farm in Brasília/DF, Brazil, caused by the excess feed provided, fish overpopulation and absence of aeration systems. The deaths were caused by hypoxia found in 4 of the 5 existing fish pond after analyzing the dissolved oxygen concentration in each unit. This fact highlights the importance of water analysis kits when attending to suspected fish diseases, as it is an important differential diagnosis, especially in cases of high mortality. Another finding was the presence of hepatic steatosis in the eight necropsied tilapias, confirmed by the observation of fatty degeneration of hepatocytes in histopathological assays.
\end{abstract}

Keywords: Oreochromis niloticus, hepatic steatosis, incorrect handling, official veterinary service

\section{Introdução}

A tilápia do Nilo (Oreochromis niloticus), originária do Rio Nilo, na África, é o peixe mais cultivado do Brasil e um dos mais consumidos em todo o mundo. Segundo dados do IBGE (2019), a produção brasileira de carne de tilápia em 2018 foi de 311.540 toneladas, crescimento de $10,78 \%$ em relação à 2017. Esse volume representa $60 \%$ de toda produção nacional de peixes e mantém o país em posição de 
destaque na produção desta espécie. Atualmente, o Brasil ocupa o posto de $4^{\circ}$ maior produtor deste peixe no mundo, atrás apenas de China, Indonésia e Egito (PEIXE-BR, 2020). Trata-se de uma espécie onívora, rústica, que suporta baixos níveis de oxigênio e altas concentrações de amônia dissolvidas na água e que apresenta precocidade sexual, iniciando a reprodução com cerca de 4 a 6 meses de idade (Kubitza, 1999). Além disso, a tilápia é bastante exigente nutricionalmente, requerendo níveis elevados

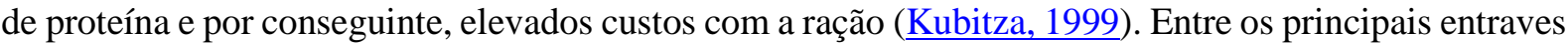
encontrados na tilapicultura estão os desafios sanitários e as falhas de manejo, responsáveis por altas taxas de mortalidade e pelo baixo desempenho produtivo. A demanda cada vez maior por pescado exige melhorias nos sistemas de produção (Naylor et al., 2000), especialmente em pontos importantes como aeração, qualidade físico-química da água e manejo alimentar (Iwashita \& Maciel, 2013).

As mortalidades em peixes causam enormes prejuízos aos criadores e à cadeia produtiva e podem estar relacionadas a falhas de manejo e/ou doenças provocadas por parasitas, bactérias, fungos ou vírus. Por isso, são objetos de investigação pelos serviços veterinários em busca de doenças de interesse oficial como Estreptococose, Franciselose, Aeromonose, Columnariose, Tilapia Lake Virus (TiLV), Necrose Infecciosa do Baço e Rim (ISKNV) e outras enfermidades causadoras de altas taxas de mortalidade. Nesse contexto, as mortalidades causadas por falhas de manejo aparecem como principal diagnóstico diferencial em sistemas intensivos de produção animal (Watanabe et al., 2002). Dentre as principais falhas de manejo causadoras de mortalidades em peixes, estão o arraçoamento inadequado, geralmente excessivo, e o excesso de matéria orgânica; déficit de oxigênio dissolvido na água decorrente da ausência de sistemas de aeração ou disponibilização de níveis insuficientes; estresse fisiológico provocado por trocas de água, choques de temperatura e excesso de manipulação dos animais; e falhas no sistema de biosseguridade (Meyer \& Barclay, 2009). O presente artigo tem como objetivo relatar o caso de mortalidade ocorrida em um criatório de tilápias do Nilo provocada por falhas de manejo decorrentes de arraçoamento inadequado e superpopulação, bem como transmitir um alerta aos serviços veterinários oficiais quanto a importância desse diferencial durante as investigações de doenças de notificação obrigatória.

\section{Relato de caso}

O Serviço Veterinário Oficial do Distrito Federal (SVO/DF) é representado pela Diretoria de Sanidade Agropecuária e Fiscalização, subordinada à Secretaria de Agricultura, Abastecimento e Desenvolvimento Rural (SEAGRI/DF). O órgão é responsável pelas investigações oficiais das síndromes e suspeitas de doenças-alvo de diferentes grupos taxonômicos, entre eles os peixes, no âmbito distrital. Em agosto de 2019, o SVO/DF recebeu uma notificação relatando grande mortalidade de tilápias em um criatório na região de Sobradinho, ao norte do Plano Piloto, Distrito Federal. O produtor informou que a mortalidade se deu de forma aguda, e que havia perdido cerca de $30 \%$ dos peixes em menos de 48 horas. Poucas horas depois da comunicação, uma equipe do SVO/DF visitou a propriedade para iniciar a investigação sobre as causas da grande mortalidade.

Um dos papeis dos serviços veterinários é confirmar ou descartar as suspeitas fundamentadas de doenças de notificação obrigatória contidas na Portaria MPA n ${ }^{\circ} 19$ de 2015. Na anamnese, foi constatado que não houve entrada de peixes ou outros animais aquáticos nos últimos três anos e que a água da piscicultura era oriunda de uma mina cuja nascente encontrava-se dentro da propriedade. Assim, foi previamente descartada a possibilidade de se tratar de doença-alvo, uma vez que a introdução deste tipo de enfermidade se dá mediante trânsito de peixes, animais aquáticos ou abastecimento da piscicultura com águas de superfície contaminadas (RENAQUA, 2015).

A piscicultura, majoritariamente usada para subsistência, contava com cinco tanques escavados impermeabilizados, de aproximadamente $200 \mathrm{~m}^{3}$, em sistema semi-fechado e canais abertos utilizando o relevo acidentado e a gravidade para abastecimento, com fluxo contínuo da água, que passava por todos eles, do primeiro até o quinto. Antes da ocorrência, havia aproximadamente 3000 tilápias-do-Nilo de diferentes idades distribuídas pelas cinco unidades e cerca de 100 surubins em policultivo com as tilápias no $5^{\circ}$ tanque. Houve mortalidade no $2^{\circ}, 3^{\circ}, 4^{\circ}$ e $5^{\circ}$ tanque. O primeiro tanque, cujo nível do relevo encontrava-se acima dos demais e primeiro a receber a água da mina, não apresentou morte de peixes, tampouco sinais clínicos. Os demais tiveram mortalidade estimada entre 40 e $100 \%$, conforme ilustração da figura 1. 


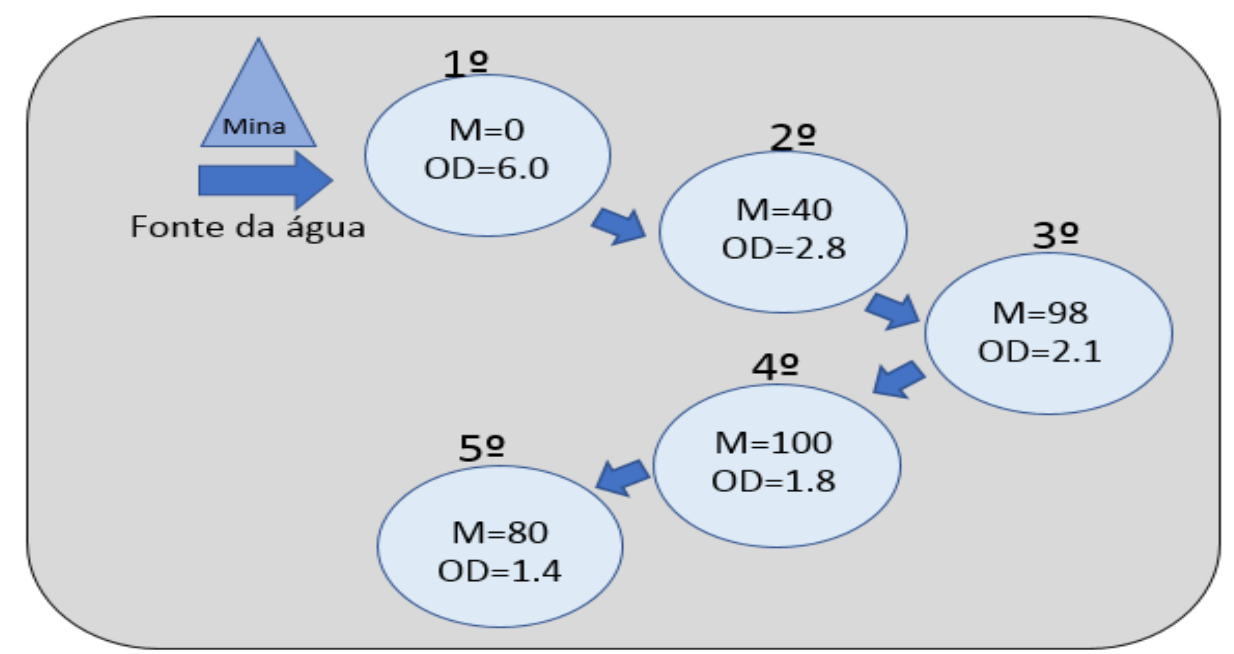

Figura 1. Representação gráfica dos cinco tanques da propriedade; setas azuis indicam o fluxo da água por gravidade; $\mathrm{M}$ = Índice de Mortalidade (em \%) estimado de tilápias 72h após o início da ocorrência; e $\mathrm{OD}=$ Concentração de Oxigênio Dissolvido (em mg/L) do respectivo tanque às 7 h00 da manhã.

Durante dois dias de investigação, foi estimada a mortalidade de $70 \%$ das tilápias da propriedade e $10 \%$ dos surubins. Foram observados peixes de diferentes idades em decúbito lateral no fundo dos tanques, tilápias com pele escurecida, alguns indivíduos ofegantes, letárgicos e apresentando perda de equilíbrio e natação anômala. Utilizando puçás, capturamos oito tilápias moribundas para inspeção clínica. À necropsia, foram observados estômagos vazios indicando estado de anorexia e fígados com coloração amarelada, variando do aspecto pálido à tonalidade amarela intensa (Figura 2). Não foram encontradas outras alterações macroscópicas dignas de nota. Fragmentos com tamanho de $2 \times 2 \mathrm{~cm}$ de fígado, brânquias, rim, coração e baço foram colhidos e fixados em solução com formol a $10 \%$ para análise histopatológica no Laboratório de Anatomia Patológica Veterinária da União Pioneira de Integração Social - UPIS, Brasília/DF. Achados histopatológicos foram encontrados apenas nas amostras de fígado. Foram observados hepatócitos tumefeitos, com citoplasma vacuolizado e núcleo ora deslocado para a periferia e condensado, ora central e arredondado (Figura 3). Observou-se ainda vasos sanguíneos dilatados e repletos de hemácias em sua luz, caracterizando presença de congestão. O laudo apontou essa lesão acometendo aproximadamente $85 \%$ dos fragmentos examinados.
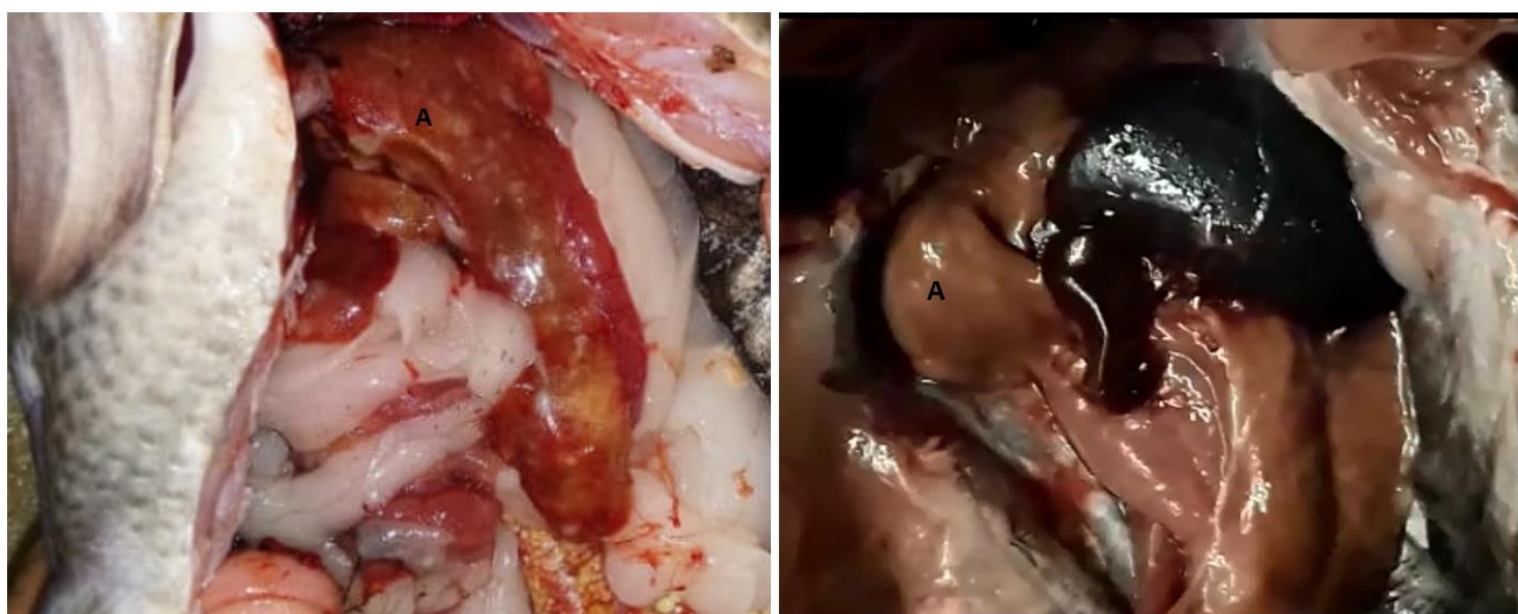

Figura 2. Fotos de fígados (A) de duas tilápias fêmeas necropsiadas, apresentando diferentes tonalidades de amarelo. A histopatologia confirmou degeneração gordurosa difusa em todas as amostras.

Concomitantemente, foi realizada a avaliação do manejo e da alimentação fornecida aos peixes. Constatou-se grande quantidade de matéria orgânica depositada no fundo dos tanques, inclusive com grânulos de ração inteiros, excesso de fezes de tilápias e ausência de sistemas de aeração. A oxigenação da água era obtida através de pequenas quedas d'água provocadas pelo abastecimento por gravidade. A 
ração utilizada era extrusada, de um fabricante nacional, ideal para fase de terminação, com alto teor de energia e baixa quantidade de proteína bruta (PB). O produtor não fazia diferenciação de fases em seu cultivo e fornecia a mesma ração para tilápias adultas, juvenis e alevinos. Outra característica verificada foi a quantidade de tilápias, que se reproduziam livremente. Segundo o criador, começou a criar há 3 anos, quando comprou um milheiro de alevinos e a partir daí os peixes cresceram, atingiram a maturidade sexual e começaram a se reproduzir gerando formas jovens e tilápias de todos as idades. $\mathrm{O}$ $\mathrm{SVO} / \mathrm{DF}$ retornou à propriedade as $7 \mathrm{~h} 00$ da manhã para realizar a análise da água, especialmente dos níveis de oxigênio dissolvido (OD), uma vez que é durante a noite que costumam atingir os valores mais críticos. Foi utilizado um Medidor de Oxigênio Dissolvido Digital (Instrutherm) para as análises. O $5^{\circ}$ tanque apresentou o menor nível de oxigênio $(1,4 \mathrm{mg} / \mathrm{L})$. Entre o $2^{\circ}$ e $4^{\circ}$ tanque, os valores mensurados variaram entre 1,8 e 2,8 mg/L. Já o primeiro tanque, encontrava-se com $6 \mathrm{mg} / \mathrm{L}$ de oxigênio dissolvido na água e qualidade bem superior aos demais (Figura 1).

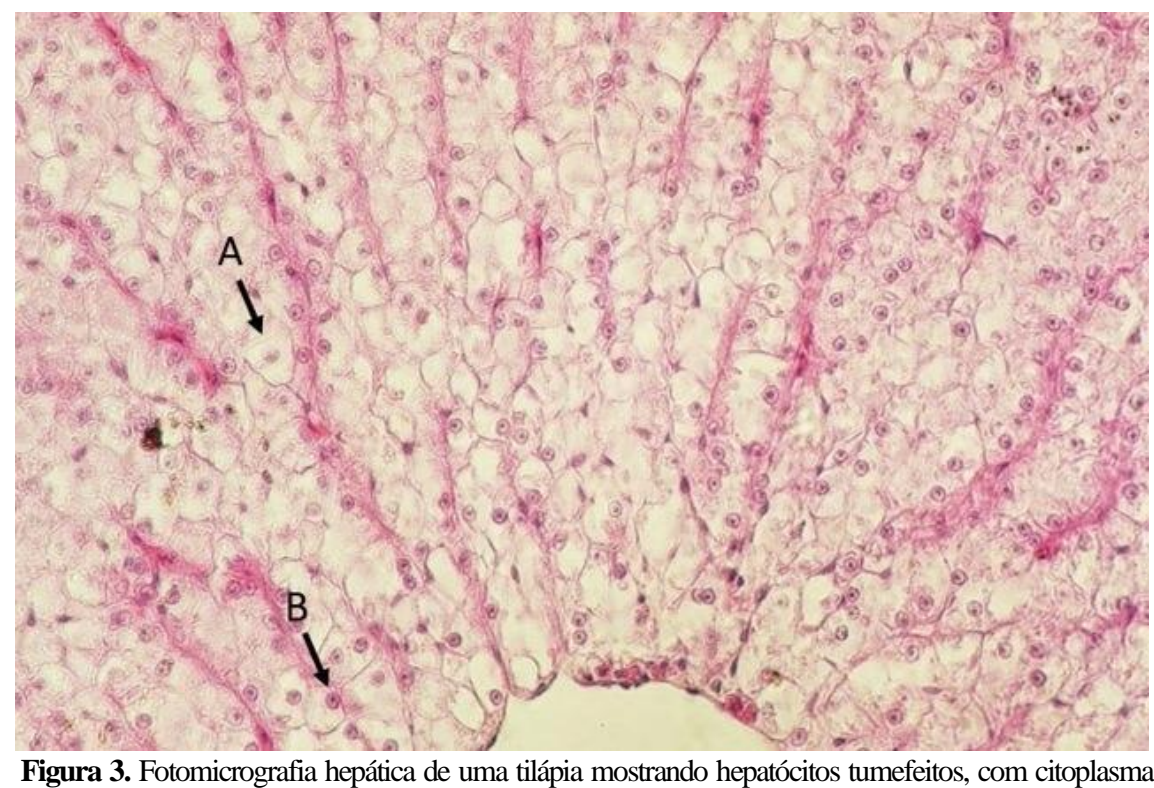

Figura 3. Fotomicrografia hepática de uma tilápia mostrando hepatócitos tumefeitos, com citoplasma vacuolizado e núcleo ora central (seta A), ora periférico e hipercromático (seta B). H\&E 100x.

\section{Discussão}

As tilápias eram criadas de forma livre, com machos e fêmeas adultas se reproduzindo constantemente e em convívio com alevinos e juvenis em todos os tanques. Sem o conhecimento técnico necessário, o proprietário fornecia uma ração de fase de engorda, com alto teor energético, consumida por peixes de todas as idades. Como se sabe, a tilápia é um peixe onívoro, bastante exigente, que requer elevadas concentrações de proteína, especialmente nas fases de larva, alevinagem e recria (Kubitza, 1999). No geral, a espécie necessita de concentrações entre 28 e $32 \%$ PB na fase de recria, e entre 30 e $47 \%$ de PB em sua fase larval (NRC, 2011). A ração fornecida era típica de fase de engorda, com teor de $24 \%$ de PB, bem aquém das necessidades da tilápia do Nilo, sobretudo para alevinos, juvenis e adultos abaixo de 600 gramas de peso vivo. Rações de fase de engorda devem ser utilizadas apenas no final de ciclo, para terminação das tilápias, cujo período pode variar de um a dois meses, até atingirem o peso de abate, por volta de $800 \mathrm{~g}$.

As alterações observadas nos hepatócitos das tilápias evidenciam um quadro de degeneração gordurosa difusa acentuada como consequência do manejo alimentar incorreto. Em sistemas de criação intensiva, o arraçoamento com balanceamento nutricional inadequado pode causar desequilíbrio no metabolismo energético dos peixes, resultando em acúmulo de lipídios no citoplasma dos hepatócitos, evoluindo para alterações severas de degeneração gordurosa, também chamada de esteatose hepática (Li et al., 2014). A estrutura dos hepatócitos de peixes possui núcleo arredondado, localizado centralmente. As dietas com maior teor de energia afetam a morfologia e o arranjo celular das células hepáticas. Assim, quando a energia da dieta excede a capacidade dos hepatócitos de oxidar os ácidos graxos, a célula apresenta seu núcleo deslocado para a periferia (Caballero et al., 2004; Gayão et al., 2013), conforme o observado nas lâminas histológicas das tilápias deste estudo. De acordo com Kumar et al. (2008), o nível 
de energia influencia no diâmetro das gotículas lipídicas. Quanto maior o teor de energia, mais acentuado são os sinais clínicos. O mesmo estudo verificou que peixes alimentados com dieta de 4.000 $\mathrm{kcal} / \mathrm{kg}$ podem apresentar lesão celular irreversível e comprometimento do estado hígido desses animais. Estes comprometimentos na fisiologia hepática dos peixes, associados às condições de estresse em sistemas de criação intensiva, provocam depleção da imunocompetência dos animais, favorecendo o surto de enfermidades por agentes etiológicos oportunistas (Belo et al., 2014). Jauncey \& Ross (1982) demonstraram que dietas com $24 \%$ de PB podem proporcionar taxas de crescimento de $80 \%$ para alevinos de Oreochromis mossambicus com peso entre 0,5 e 10 gramas. Entretanto, sistemas intensivos, como o caso do presente relato, necessitam de dietas com níveis maiores de proteína uma vez que a densidade de peixes é maior e a disponibilidade de plâncton é menor para suprir suas necessidades nutricionais (Fitzsimmons, 2000). Outra falha detectada foi na quantidade de ração fornecida. $\mathrm{O}$ produtor fazia o arraçoamento com frequência e quantidades exageradas, gerando acúmulo de deposição de ração no fundo dos tanques e, por consequência, contribuía para o excesso de matéria orgânica e microrganismos. De acordo com Boyd \& Tucker (2012), o maior aporte de ração e o excesso de matéria orgânica na água pode levar ao excesso de fitoplâncton, que também consome oxigênio; à baixa concentração de oxigênio dissolvido e à alta concentração de amônia, que é tóxica para os peixes.

Para evitar a degeneração gordurosa do fígado das tilápias, o produtor foi orientado a fornecer ração com pelo menos $28 \%$ de PB e menor teor de energia, uma vez que os peixes não estão segmentados por fases - peso e idade - para permitir o fornecimento de rações de diferentes fases com diferentes níveis proteicos. Além da qualidade da ração, o arraçoamento também foi ajustado. $O$ fornecimento da ração foi interrompido por sete dias para controle do fitoplâncton e melhora da qualidade da água. Após esse tempo, foi orientado a reintroduzir a nova ração com fornecimento de 4 a 6 vezes ao dia em quantidade moderada, suficiente para alimentar os peixes de forma que não fique sobras de ração na água. Em sistemas tecnificados, com separação por idade, é possível determinar a frequência e quantidade do arraçoamento para cada fase (Hayashi et al., 2004). Embora a degeneração gordurosa possa ocasionar perda da homeostasia, descompensação metabólica e imunossupressão, e com isso levar a quadros clínicos mais severos com mortalidade, a principal causa de morte das tilápias estava relacionada ao déficit de oxigênio dissolvido verificado em quatro dos cinco tanques.

$\mathrm{O}$ acúmulo de matéria orgânica depositada no fundo dos tanques evidenciava o excesso de ração fornecida aos peixes. A grande quantidade de matéria orgânica na água consome grande parte do oxigênio disponível, através da oxidação química e principalmente da bioquímica, via respiração dos microrganismos (Valente et al., 1997). Associado a isso, foi constatada uma superpopulação de tilápias, com machos e fêmeas adultos se reproduzindo constantemente ao longo desses três anos. De acordo com Mair et al. (1995), quando não é realizado manejo e controle reprodutivo, é comum a ocorrência de superpopulações da espécie devido à alta capacidade de reprodução, maturidade sexual precoce (anterior aos seis meses de idade) e fecundidade elevada. Iwashita \& Maciel (2013) recomendam uma densidade de estocagem de 2.000 a 3.500 peixes por hectare para sistemas de produção sem aeração. Acima disso, só é possível manter a produção com o uso de aeradores. Portanto, as condições encontradas provavelmente levaram a uma condição de hipóxia na água, devido ao grande consumo de oxigênio. De acordo com a Iwashita \& Maciel (2013), o OD é obtido por penetração direta do ar atmosférico na água, pela mistura mecânica provocada pela ação dos ventos, por correntes naturais de massas hídricas e agitações causadas pela topografia do terreno ou por meio de sistemas de aeração utilizando diversos tipos de aeradores que injetam ar diretamente na água de produção. A concentração do oxigênio na água varia com a sua temperatura e sua solubilidade depende da pressão atmosférica e da salinidade da água.

Os cinco tanques da propriedade não possuíam qualquer sistema de aeração e existiam apenas pequenas quedas e cascatas de água entre um taque e outro, decorrentes do relevo acentuado e da gravidade. Provavelmente, a água se manteve com ótima qualidade por muito tempo, quando a quantidade de peixes ainda era baixa a ponto de manter o OD em níveis continuadamente elevados. A partir do momento que a população de tilápias cresceu desenfreadamente, e com ela os excessos de matéria orgânica provocados pelo acúmulo de ração e fezes, o sistema de criação passou a sofrer com déficits de OD, geralmente acentuados durante a noite. Durante o dia, o oxigênio é produzido por fotossíntese, processo através do qual as algas transformam o gás carbônico e a água em oxigênio e 
carboidratos na presença da luz. À noite, ocorre o processo inverso, o oxigênio produzido durante o dia é consumido pela respiração de peixes e plânctons e por isso os teores de OD podem cair bruscamente para níveis críticos (Iwashita \& Maciel, 2013).

A avaliação da concentração de oxigênio, expressa em mg/L (método de Winkler), é um tipo de análise química realizada com auxílio de um oxímetro que expressa a concentração em termos de porcentagem de saturação. A avaliação empírica pode ser realizada através do monitoramento do comportamento dos peixes ao amanhecer, quando ficam agrupados próximos à entrada da água no tanque, que é o local que possui maior concentração de oxigênio (Iwashita \& Maciel, 2013). Neste caso, foram observadas centenas de tilápias aglomeradas na entrada da água dos tanques (Figura 4), corroborando com as descrições mencionadas acima.

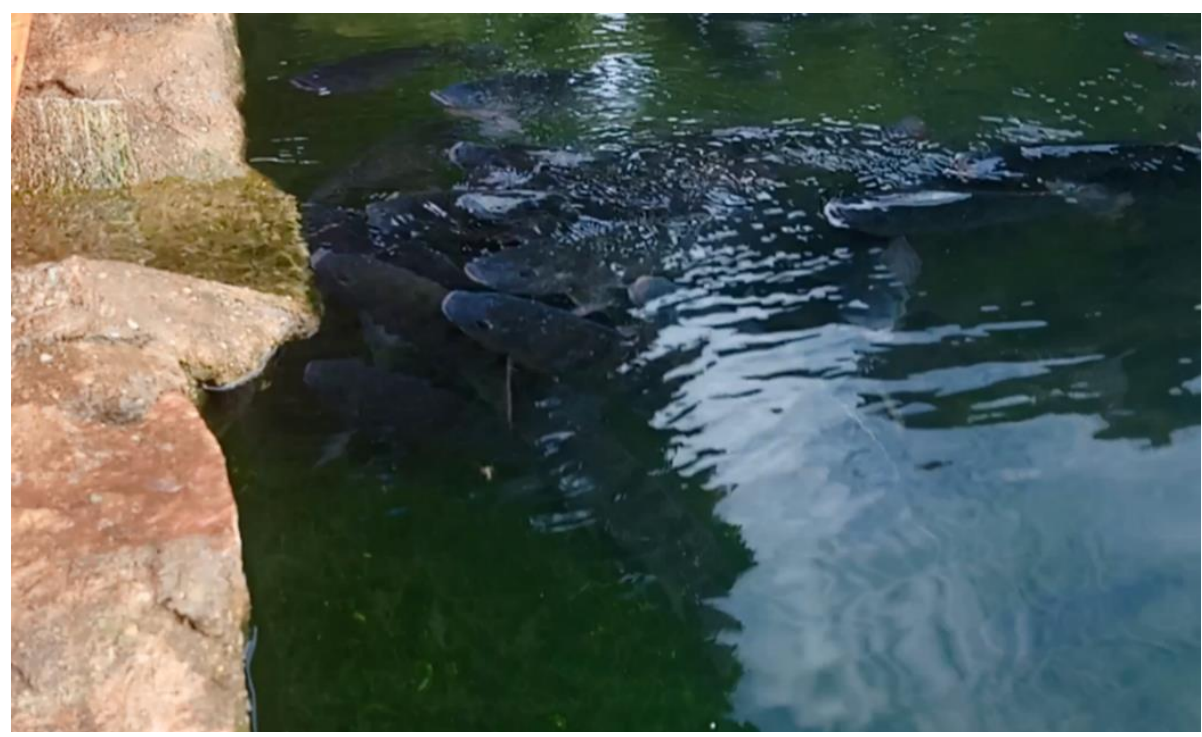

Figura 4. Tanque 5 apresentando concentração de tilápias letárgicas e ofegantes no local de desembocadura da água de abastecimento. Registro realizado às 7h00 da manhã. $\mathrm{OD}=1,4 \mathrm{mg} / \mathrm{L}$.

O SVO/DF realizou as análises químicas (OD, pH, transparência, dureza, amônia, nitrito e nitrato) e constatou níveis críticos de OD durante o início da manhã, que variaram de 1,4 a 2,8 mg/L entre os tanques $2,3,4$ e 5 . A mortalidade elevada nos quatro tanques foi causada provavelmente pelos níveis críticos de OD. Segundo Connell et al. (2005), as concentrações mínimas de OD para sobrevivência dos peixes é de 1,3 a 2,9 mg/L. Stachiw et al. (2014) descrevem que a maioria dos peixes vive bem na faixa acima de $5 \mathrm{mg} / \mathrm{L}$ e que somente os peixes mais resistentes conseguem tolerar níveis de OD abaixo de 3 $\mathrm{mg} / \mathrm{L}$, o que explica o fato de algumas tilápias terem sobrevivido. Por fim, define os níveis abaixo de 1 $\mathrm{mg} / \mathrm{L}$ de OD como letais para os peixes.

O diagnóstico de mortalidade por asfixia decorrente do déficit de oxigênio dissolvido só foi possível graças à disponibilidade de um kit de análise de água que possibilitou a constatação dos níveis críticos encontrados em quatro dos cinco tanques. Sem tal aparato, o serviço veterinário provavelmente encontraria dificuldades para descartar uma suspeita fundamentada de doença-alvo, o que obrigaria a colheita de amostras e envio para o laboratório oficial. O Manual de Coleta e Remessa do extinto Ministério da Pesca e Aquicultura e as demais normativas sanitárias não preveem kits de análise de água entre os materiais necessários para atendimento de suspeita de doenças-alvo. Por se tratar de uma frequente causa de mortalidade em peixes, é altamente recomendável aos serviços veterinários oficiais a disponibilidade de kit para mensuração de oxigênio dissolvido, amônia, nitrato, nitrito e outros compostos tóxicos para os peixes para utilização em investigações de doenças de notificação obrigatória. As análises de qualidade da água juntamente com a avaliação clínica e epidemiológica podem permitir melhores direcionamentos das prováveis causas de mortalidade e mesmo o descarte de suspeitas de doenças-alvo dos peixes.

Após a constatação da mortalidade devido ao déficit de OD, o produtor foi orientado a implantar um sistema de aeração para evitar queda no nível de oxigênio especialmente durante a noite. Foi improvisada uma estrutura para proporcionar maior queda d'água a partir de um sistema de tubos e 
calhas com elevação de 1,5 m acima do nível da água, para permitir maior penetração de oxigênio. A população de tilápias também necessitou de controle populacional. Embora tenha ocorrido grande perda de peixes, o criador foi orientado a soltar quatro exemplares de espécies predadoras de alevinos para evitar nova superpopulação. A espécie indicada foi o Dourado (Salminus brasiliensis). Além disso, foi recomendado o esvaziamento de todos os tanques para remoção da matéria orgânica, tratamento com cal virgem e vazio sanitário, conforme procedimentos descritos pela (Iwashita \& Maciel, 2013). As medidas mencionadas neste parágrafo, associadas ao ajuste de arraçoamento, cessaram os óbitos.

\section{Conclusão}

Falhas no sistema de produção decorrente de manejo alimentar inadequado podem levar ao desenvolvimento de degeneração gordurosa hepática em tilápias, que promovem a perda da homeostasia e enfraquecimento do sistema imunológico dos peixes. O excesso de ração fornecida com acúmulo de matéria orgânica e a superpopulação de peixes podem levar a condições de hipóxia na água, causando mortalidades elevadas. Essas falhas de manejo são relativamente comuns, se tornando importantes diferenciais em investigações oficiais de mortalidade em tilápias. Apesar dos kits de análise rápida de água não estarem entre os itens solicitados pelos manuais de vigilância, coleta e remessa do Ministério da Agricultura, Pecuária e Abastecimento, são altamente recomendados para os serviços veterinários oficiais, uma vez que podem auxiliar os profissionais de sanidade durante as investigações de mortalidade.

\section{Referências bibliográficas}

Belo, M. A. A., Moraes, F. R., Yoshida, L., Prado, E. J. R., Moraes, J. R. E., Soares, V. E., \& Silva, M. G. (2014). Deleterious effects of low level of vitamin E and high stocking density on the hematology response of pacus, during chronic inflammatory reaction. Aquaculture, 422, 124-128. https://doi.org/10.1016/j.aquaculture.2013.12.013.

Boyd, C. E., \& Tucker, C. S. (2012). Pond aquaculture water quality management. Springer Science \& Business Media.

Caballero, M. J., Izquierdo, M. S., Kjørsvik, E., Fernandez, A. J., \& Rosenlund, G. (2004). Histological alterations in the liver of sea bream, Sparus aurata L., caused by short-or long-term feeding with vegetable oils. Recovery of normal morphology after feeding fish oil as the sole lipid source. Journal of Fish Diseases, 27(9), 531-541. https://doi.org/10.1111/j.1365-2761.2004.00572.x.

Connell, D. W., Connell, D. W., Vowles, P. D., Warne, M. S. J., \& Hawker, D. W. (2005). Basic concepts of environmental chemistry. Boca Raton, CRC Press.

Fitzsimmons, K. (2000). Tilapia: the most important aquaculture species of the 21st century. Proceedings from the Fifth International Symposium on Tilapia Aquaculture, 1, 3-8.

Gayão, A. L. B. A., Buzollo, H., Fávero, G. C., Junior, S., Araújo, A., Portella, M. C., Cruz, C., \& Carneiro, D. J. (2013). Histologia hepática e produção em tanques-rede de tilápia-do-nilo masculinizada hormonalmente ou não masculinizada. Pesquisa Agropecuária Brasileira, 48, 991997. https://doi.org/10.1590/S0100-204X2013000800026.

Hayashi, C., Meurer, F., Boscolo, W. R., Lacerda, C. H. F., \& Kavata, L. C. B. (2004). Freqüência de arraçoamento para alevinos de lambari do rabo-amarelo (Astyanax bimaculatus). Revista Brasileira de Zootecnia, 33, 21-26. https://doi.org/10.1590/s1516-35982004000100004.

IBGE. Instituto Brasileiro de Geografia e Estatística. Produção da Aquicultura 2018. Brasília, 2019. Disponível em: https://sidra.ibge.gov.br/tabela/3940 Acesso em 13 nov. 2019.

Iwashita, M. K. P., \& Maciel, P. O. (2013). Princípios básicos de sanidade de peixes. In A. P. O. Rodrigues, A. F. Lima, A. L. Alves, D. K. Rosa, L. S. Torati, \& V. R. V Santos (Eds.), Piscicultura de água doce: multiplicando conhecimento (Iwashita, Vol. 7, pp. 215-269). Embrapa.

Jauncey, K., \& Ross, B. (1982). A guide to tilapia feeds and feeding. University of Stirling.

Kubitza, F. (1999). Nutrição e alimentação dos peixes cultivados (Vol. 1).

Kumar, V., Abbas, A. K., Fausto, N., \& Mitchell, R. N. (2008). Robbins patologia básica. Elsevier Brasil. 
Li, J., Zhang, D., Xu, W., Jiang, G., Zhang, C., Li, X., \& Liu, W. (2014). Effects of dietary choline supplementation on growth performance and hepatic lipid transport in blunt snout bream (Megalobrama amblycephala) fed high-fat diets. Aquaculture, 434, 340-347. https://doi.org/10.1111/anu.12231.

Mair, G. C., Abucay, J. S., Beardmore, J. A., \& Skibinski, D. O. F. (1995). Growth performance trials of genetically male tilapia (GMT) derived from YY-males in Oreochromis niloticus L.: On station comparisons with mixed sex and sex reversed male populations. Aquaculture, 137(1-4), 313-323. https://doi.org/10.1016/0044-8486(95)01110-2.

Meyer, F. P., \& Barclay, R. J. (2009). Manual de campo para investigação de morte de peixes. In Manual de campo para investigação de morte de peixes. Compania Energética de Minas Gerais.

Naylor, R. L., Goldburg, R. J., Primavera, J. H., Kautsky, N., Beveridge, M. C. M., Clay, J., Folke, C., Lubchenco, J., Mooney, H., \& Troell, M. (2000). Effect of aquaculture on world fish supplies. Nature, 405(6790), 1017-1024. https://doi.org/10.1038/35016500.

NRC. (2011). Nutrient Requirements of Fish and Shrimp (7th rev.). Natl. Acad. Press, Washington, DC.

PEIXE-BR. (2020). Anuário Peixe BR da Piscicultura. Associação Brasileira da Piscicultura.

Renaqua. Rede Nacional de Laboratórios do Ministério da Pesca e Aquicultura. Relatório de Atividades 2012 - 2015. Brasília: MPA, 2015.

SEAGRI. Secretaria de Agricultura, Abastecimento e Desenvolvimento Rural do Distrito Federal. Informe Epidemiológico. Brasília: Coordenação de Epidemiologia - Diretoria de Sanidade Agropecuária e Fiscalização, 2018.

Stachiw, R., Silva, F. R., Vendrusculo, J., Medeiros, T. F., Tavares, V. C. C., \& Dutra, A. R. (2014). Qualidade da água de tanques de piscicultura em Rolim de Moura-RO. Revista Brasileira de Ciências Da Amazônia, 2(1), 22-34.

Valente, J. P. S., Padilha, P. M., \& Silva, A. M. M. (1997). Oxigênio dissolvido (OD), demanda bioquímica de oxigênio (DBO) e demanda química de oxigênio (DQO) como parâmetros de poluição no ribeirão Lavapés/Botucatu-SP. Eclética Química, 22, 49-66.

Watanabe, W. O., Losordo, T. M., Fitzsimmons, K., \& Hanley, F. (2002). Tilapia production systems in the Americas: technological advances, trends, and challenges. Reviews in Fisheries Science, 10(34), 465-498. https://doi.org/http://dx.doi.org/10.1080/20026491051758.

Histórico do artigo:

Recebido: 1 de junho de 2021

Aprovado: 9 de junho de 2021
Licenciamento: Este artigo é publicado na modalidade Acesso Aberto sob a licença Creative Commons Atribuição 4.0 (CC-BY 4.0), a qual permite uso irrestrito, distribuição, reprodução em qualquer meio, desde que o autor e a fonte sejam devidamente creditados. 